\title{
Sim Investigador: Um jogo construcionista
}

\author{
Carlos A. C. Lessa Filho ${ }^{1}$, Arturo Hernández Domínguez ${ }^{1}$, Fabio P. D. da Costa1, \\ Patrícia V. T. de A. Oliveira ${ }^{2}$ \\ ${ }^{1}$ Universidade Federal de Alagoas (UFAL) \\ Maceió - AL - Brasil \\ ${ }^{2}$ Centro Universitário CESMAC \\ Maceió - AL - Brasil \\ carloswgama@gmail.com, arturohd@uol.com.br, \\ fabioparagua2000@gmail.com, pattyvirginia@hotmail.com
}

\begin{abstract}
This paper presents an educational game, Sim Investigador, based on constructionism, for students in elementary and secondary education. The game allows students to play the role of a detective and enables acquiring knowledge through solving cases in the context of a discipline. The game developed was used by 49 students. The results were satisfactory, most students expressed that felt more motivated to studies using the game. The game developed represents a new resource that can support the teacher and the student in the teaching-learning process.
\end{abstract}

Resumo. Este artigo apresenta um jogo educativo, Sim Investigador, baseado no construcionismo, para estudantes do ensino fundamental e médio. O jogo permite ao estudante assumir o papel de um investigador e possibilita adquirir conhecimento através da resolução de casos no contexto de uma disciplina. O jogo desenvolvido foi utilizado por 49 estudantes. Os resultados foram satisfatórios a maioria dos estudantes manifestou que se sentia mais motivada nos estudos com o uso do jogo. O jogo desenvolvido representa uma ferramenta que possa dar suporte ao professor e o estudante no processo de ensino-aprendizagem.

\section{Introdução}

O uso do computador na educação tem se tornado uma ferramenta agregada ao processo de ensino, que auxilia o professor e o estudante na construção do conhecimento [Anacleto et al 2008]. Em 1997 de acordo com os Parâmetros Curriculares Nacionais (Brasil, 1997) já se demonstrava a preocupação com a integração dos estudantes com este recurso na aprendizagem, considerando-o um instrumento de aprendizagem escolar necessário para atualizar o estudante em relação às novas tecnologias da informação para atender as demandas sociais presentes e futuras.

Nesse contexto, do computador no processo de desenvolvimento do aprendizado do estudante, destaca-se a abordagem construcionista [Papert e Harel 1991]. O construcionismo defende a ideia de aprender por meio da construção, sendo o computador uma ferramenta importante para a elaboração de um material concreto. Ainda de acordo com a dupla, uma criança teria mais relutância em aprender o conteúdo que foi passado pela escola em comparação ao que é transmitido através dos jogos da Nintendo, entendendo-se a importância do uso do lúdico no processo de aprendizagem. 
Neste contexto, a proposta deste trabalho é o desenvolvimento de um ambiente lúdico em forma de jogo que permita aos estudantes de ensino fundamental e médio adquirirem o conhecimento através da construção de histórias sobre o assunto de uma disciplina. O objetivo do desenvolvimento deste ambiente é possibilitar que estudantes e professores possuam novos recursos que possam ser agregados às aulas de forma a motivarem os estudantes através do lúdico, incentivar o raciocínio e reflexão por meio da construção e que os professores possam acompanhar o desenvolvimento de seus estudantes.

\section{Construcionismo}

O construcionismo de Seymour Papert surgiu a partir do construtivismo de Jean Peaget, biólogo que estudou as fases do conhecimento no humano com uma visão biológica. Ao contrário da visão do empirismo e apriorismo, o construtivismo de Jean Piaget analisou o humano como um ser biológico de forma que o conhecimento viria do sujeito ao atingir certa faixa etária [Rizzon 2009].

O construcionismo criado por Seymour Papert, matemático que trabalhou junto a Piaget, tem uma visão um pouco diferenciada, onde além de compreender as fases do desenvolvimento, também observa o educando como o sujeito que deve construir algo para gerar o seu próprio conhecimento por intermédio de alguma ferramenta. $\mathrm{O}$ construtivismo [Kafai 2006] prioriza o desenvolvimento de estruturas de conhecimento isoladas e individuais, e o construcionismo objetiva a natureza conectada do conhecimento com dimensões pessoais e sociais. O construcionismo de Papert considera aprendizagem como a construção de relações entre o velho e o novo conhecimento, nas interações com outros, criando artefatos de relevância social.

\section{Trabalhos Relacionados}

Para Clua e Bittencourt (2004) a atratividade dos jogos eletrônicos, na maioria dos casos, é devida ao desafio imposto pelo jogo. O funcionamento de um jogo eletrônico é governado através de um conjunto de regras. Essas regras definem o que os jogadores podem e o que eles não podem fazer no decorrer do jogo eletrônico. Na aprendizagem baseada em jogos eletrônicos os jogadores aprendem a fazer coisas. Segundo Prensky (2001) os jogadores assimilam informações e tomam decisões rapidamente, também deduzem as regras do jogo.

Nos últimos anos, alguns jogos têm sido desenvolvido com o proposito de auxiliar no processo de ensino, como é o caso de MoviLetrando e SPARSE.

MoviLetrando [Farias et al. 2013] é um jogo desenvolvido considerado "Jogo Sério”, que são jogos com uma finalidade maior do que o entretenimento. O jogo tem como público alvo crianças com Síndrome de Down, com objetivo de contribuir com os primeiros passos de letramento dessas crianças.

Um jogo construcionista é o SPARSE [Souza et al. 2010], jogo desenvolvido como uma abordagem prática para o ensino e aprendizado de Engenharia de Software. O jogo simula a construção e gerenciamento de um projeto envolvendo os elementos essenciais do desenvolvimento de um projeto. 


\section{Metodologia}

Com a finalidade de decidir quais módulos o jogo deveria possuir, foi realizado uma análise de jogos educativos para obter pontos positivos e negativos. Após esta análise foram escolhidos os módulos e a linguagem utilizada no desenvolvimento desse jogo, PHP (Hypertext PreProcessor).

Para validação foram selecionados 49 estudantes do ensino fundamental, sendo estes estudantes do ensino fundamental, e três professores. No primeiro contato com os estudantes foi apresentada a ideia do jogo Sim Investigador e uma explicação de suas funcionalidades. Após a explicação, foi solicitado que estes estudantes jogassem uma das histórias já criadas previamente, para que compreendessem o jogo e após esta etapa, foi demonstrado como poderiam construir suas próprias histórias. Ao finalizar a demonstração, os estudantes deveriam responder um questionário disponibilizado no próprio ambiente, envolvendo perguntas relacionados as metodologias de ensino, motivações no processo de aprendizagem e sobre o jogo. Os professores também foram convidados para responder um questionário sobre as perspectivas dos professores, questões sobre os problemas na educação e o uso de recursos lúdicos.

\section{O jogo construcionista: Sim Investigador}

O desenvolvimento do jogo proposto Sim Investigador ${ }^{1}$ (Figura 1) teve início em 2012. O jogo possui como proposta criar um ambiente onde professores e alunos possam interagir entre si através de histórias criadas pelos próprios usuários e que contenham algum conteúdo de uma disciplina do ensino fundamental ou médio.

Em Sim Investigador o jogador assumirá o papel de um investigador que precisará resolver casos (Figura 2) criados pelos usuários, através de questões no contexto de uma disciplina.

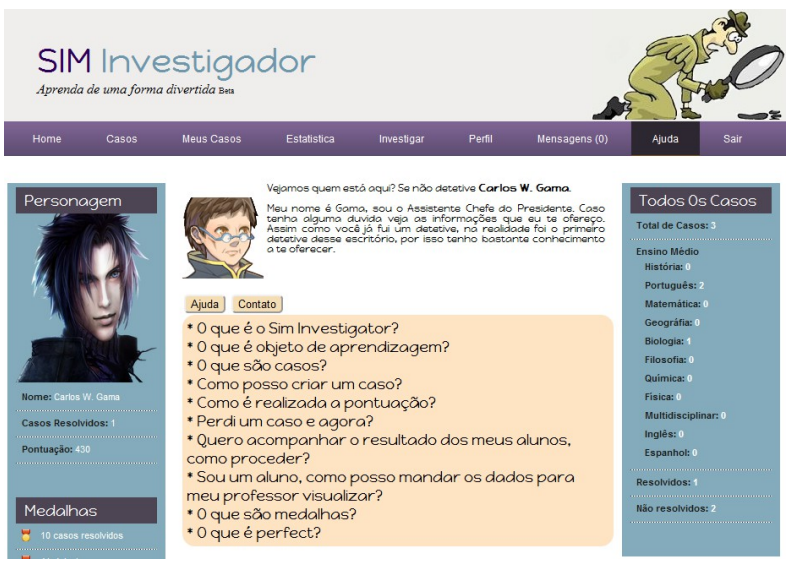

Figura 1 - Visão Geral Sim Investigador

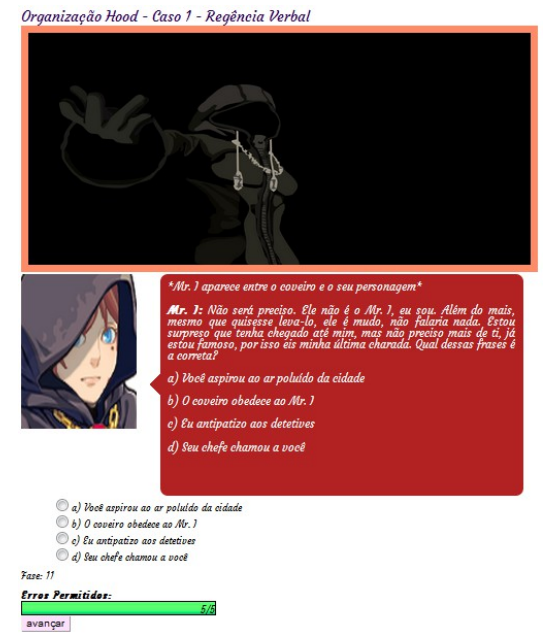

Figura 2 - Resolvendo um caso

O destaque para o jogo está no fato de que cada usuário pode criar sua própria história (chamadas de caso) associada a alguma disciplina. Desta forma o professor, assumindo um papel de tutor, poderá incentivar seus estudantes a pôr em prática o que foi visto em sala de aula, propondo e direcionando temas sobre a disciplina. Isto

1 O jogo pode ser encontrado através do endereço www.siminvestigador.com.br 
resultaria em realizar uma atividade construcionista que levaria aos estudantes a se aprofundar no conteúdo estudado.

O desenvolvimento de um caso pode ser motivado por um problema (sugerido pelo professor) ou dúvida que o usuário já tenha presenciado de forma que contextualize o que se deseja estudar. Após criar uma história, esta poderá ser avaliada por um professor, caso solicitado, e sendo aprovada, ficará disponível na base do jogo, para os demais usuários poderem ter acesso.

Além de poder jogar uma história criada e desenvolver uma própria, nas respectivas seções "Casos" e "Meus Casos", o jogo ainda conta com recursos como personalização de perfil, troca de mensagens, estatísticas, seguir os casos resolvidos por um usuário (menu investigar), uma seção para dúvidas relacionadas ao jogo e um sistema de conquista em fase de desenvolvimento, facilmente encontrados no menu principal do jogo. Cada uma dessas seções é representada por um personagem do jogo para auxiliar o usuário e contribuir para ambientação.

\section{Resultados e Discussão}

Após obter os resultados dos questionários aplicados, relacionados ao aprendizado em sala de aula e sobre o uso do jogo Sim Investigador, pode-se constatar em relação ao ensino em sala que a maioria dos estudantes não sente dificuldades em aprender através de livros e explicações no quadro (Figura 3). Porém aos estudantes que responderam que sentem dificuldade, observou-se que suas dificuldades estão vinculadas a não conseguir assimilar o conteúdo da forma apresentada pelo professor. Também foi possível observar que os estudantes tendem a esquecer do que foi estudado no ano anterior, demonstrando uma preocupação com a nota ao invés do aprendizado. Ao questionar os professores sobre a maior dificuldade que eles encontram em transmitir o conteúdo para os estudantes, foi informado sobre a falta de recursos diferenciados para se usar em sala de aula e a dificuldade em prender a atenção do estudante.

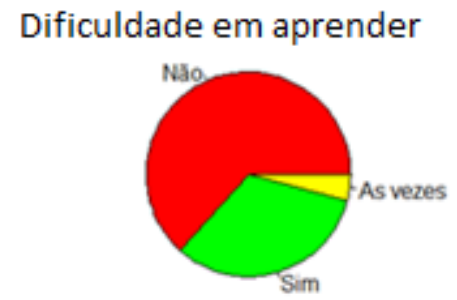

Esquece o que foi estudado

Figura 3 - Dificuldades no ensino

Através dos questionários pode-se observar relacionado ao uso do jogo Sim Investigador que 34 dos 49 estudantes nunca tinham tido contato com jogos parecidos voltados a educação e 38 estudantes informaram se sentir mais motivados aos estudos contra 9 que informaram preferir o ensino através de quadro e livros e o restante optando pela união das duas formas.

No contexto da possibilidade da construção de histórias pelos próprios usuários, verificou-se uma grande aceitação por parte dos estudantes, representando 46 dos 49 estudantes e os três professores informaram gostar da ideia da possibilidade dos estudantes construírem suas próprias histórias.

Entre as opiniões relacionadas ao jogo, pode-se observar uma grande satisfação com o contato que tiveram com o jogo devido ao fato de ser uma forma divertida de 
aprender, porém houve sugestões quanto à possibilidade de ter menos texto e mais dinamismo como a possibilidade de andar com o personagem dentro de um cenário.

\section{Conclusão}

Neste artigo, foi proposto e desenvolvido o jogo Sim Investigador que é baseado no construcionismo. O jogo desenvolvido passa a liberdade para o estudante e o leva a refletir sobre o que está sendo trabalhando, o estudante adquire conhecimento através da resolução de casos (construção de histórias) no contexto de uma disciplina. Os casos a serem resolvidos podem surgir como sugestões pelo professor no contexto de um curso semipresencial ou à distância.

Durante as avaliações realizadas com estudantes, foi observado, que existe uma preferência por eles que o jogo pudesse ter casos onde o jogador controlasse 0 personagem em vez de interagir com textos. Desta forma para projetos futuros pretendese realizar uma reformulação no ambiente, onde as histórias possam ser jogadas em um ambiente 2D.

\section{Referências}

Anacleto, J.C., Ferreira, A.M., Pereira, E.N., Silva, M. A.R. e Fabro, J.A. (2008) "Ambiente para criação de jogos educacionais de adivinhação baseados em cartas contextualizadas.” In XVI Workshop sobre Informática na Escola (WIE), p. 29-38.

Brasil, Secretária de Educação Fundamental. (1997) "Parâmetros Curriculares Nacionais: Introdução aos Parâmetros Curriculares Nacionais”.

Clua E. W. G., Bittencourt J. R. (2004) Uma Nova Concepção para a Criação de Jogos Educativos. Minicurso do Simpósio Brasileiro de Informática na Educação 2004.

Farias E. H., Hounsell M. da S., Blume L. B., Ott, F. R. e Cordovil, F. V. P. (2013) "MoviLetrando: Jogo de Movimentos para Alfabetizar Crianças com Down". In Simpósio Brasileiro de Informática na Educação 2013.

Kafai, Y. B. (2006) “Constructionism”, In: Cambridge Handbook of The Learning Sciences. Edited by R. Keith Sawyer. Cambridge University Press. United Kingdom.

Papert, S e Harel, I. (1991) “Constructionism”, publicado por Ablex Publishing Corporation.

Prensky, M. (2001). “Digital game-based learning”. New York: McGraw-Hill.

Rizzon, G. (2009) "Investigação de Jean Piaget: A epistemologia genética e o apriorismo”. Universidade de Caxias do Sul.

Souza, M. M., Resende, R. F., Prado, L. S., Fonseca, E. F., Carvalho, F. A. e Rodrigues A. D. (2010) "SPARSE: Um Ambiente de Ensino e Aprendizado de Engenharia de Software Baseado em Jogos e Simulação”. In: Anais do Simpósio Brasileiro de Informática na Educação 2010. 